\title{
Structural retrofit of glazing systems with polymer materials for blast resistance
}

\author{
K. Marchand ${ }^{1}$, C. Davis ${ }^{1}$, E. Conrath ${ }^{1}$, P. Votruba-Drzal ${ }^{2}$, \\ E. Millero ${ }^{2} \&$ G. Yakulis ${ }^{2}$ \\ ${ }^{1}$ Protection Engineering Consultants, USA \\ ${ }^{2} P P G$ Industries, Inc., USA
}

\begin{abstract}
Protection Engineering Consultants (PEC), in cooperation with PPG Industries, Inc., is investigating the performance of a clear polymer coating material for windows subjected to blast loading. PEC developed a static test fixture and performed static tests to evaluate the retrofit window response. PEC then performed preliminary single-degree-of-freedom (SDOF) analysis, using a resistance function for the clear polymer coated glazing based on the quasi-static test results. Dynamic (full-scale blast) tests were then performed in Yancey, Texas with the assistance of Southwest Research Institute (SwRI). The dynamic test results were then used to determine strain rate effects, resulting in dynamic increase factors for the static resistance functions. The clear polymer coated windows absorbed energy during the blast load through large deflections and allowed very few fragments within the test structure. This paper summarizes the test results and analysis and provides recommendations for further development of this composite glass/polymer system.
\end{abstract}

Keywords: blast loads, glass fracture, glass hazards, polymer materials.

\section{Introduction}

Monolithic (non-laminated) glass is a brittle material that shatters upon reaching fracture stress or displacement under wind, impact or explosive loads. Injury studies have demonstrated the hazards associated with skin laceration and shard blunt trauma. Materials such as polyethylene (PET) films have been used for many years to retain shards upon glass lite fracture. To have significant effect on 
hazard reduction, these PET films must not only be adhered to the glass, but must be mechanically anchored to the window supporting structure with screwattached battens or through "gluing" with materials such as structural silicone. To reduce the labor and to improve the performance of a retrofitted materials designed to reduce glass shard hazards, PPG Industries, Inc. has formulated optically clear polymer materials (coatings) that can be spray-applied to glass. An additional benefit of these materials is that the same spray application can be used to "overspray" the polymer onto supporting frames and mullions, thereby achieving the mechanical anchorage necessary for complete hazard reduction without additional materials (battens) or labor.

PPG provided material properties through dynamic mechanical analysis and Instron tensile testing of four clear polymer samples. The first sample consists of a clear polymer with a low modulus of elasticity in a thin or thick configuration, while the second sample is a clear polymer with a high modulus of elasticity. Both clear polymer formulations were incorporated into the test plan. Adhesion strength was also considered as controlled by the application of adhesion promoters to the glass and frame. Application of the adhesion promoter resulted in a high adhesion specimen with a peel-off strength of more than $25 \mathrm{lb} / \mathrm{in}$. By not applying adhesion promoter to the glass of the low adhesion specimen, the low adhesion polymer separated from the glass during dynamic response while remaining adhered to the frame. The peel-off strength was less than $5 \mathrm{lb} / \mathrm{in}$.

\section{Quasi-static tests}

Quasi-static tests were performed to generate static load-deflection curves (static resistance functions) and to determine failure mechanisms for clear polymer coated windows. Twenty-three tests were performed. The test matrix, as shown in Table 1, included 23 test specimens and considered six test variables: size of window, type of connection, glazing material, glass thickness, polymer thickness, and type of polymer. Only high adhesion, low modulus of elasticity polymer was used for the static tests.

The two nominal window sizes were 2 - $\mathrm{ft} \times 3$ - $\mathrm{ft}$ and 4 -ft $\times 4$ - $\mathrm{ft}$ (width $\times$ height), which corresponds to the following actual glazing dimensions: 24.75 -in $\times 34.75$-in and 48.75 -in $\times 47.25$-in, respectively. The type of connection refers to the connection between the aluminum window frame, glazing, and clear polymer.

All frame pieces were 6061-T6 aluminum. Connections used a 1.25 -in, 3M VHB Structural Glazing (grey) Tape G23F on both sides. When polymer was used with a "tape only" connection, the polymer coated glazing was captured within the aluminum frame, where essentially the $3 \mathrm{M}$ tape provides the only connection between the polymer-coated glazing and frame. Where "spray 4 sides" is indicated, the polymer was sprayed on the frame, providing a mechanical connection. The remaining variables pertain to the glass and polymer properties. 
Table 1: Quasi-static test matrix.

\begin{tabular}{|c|c|c|c|c|c|}
\hline \multicolumn{6}{|c|}{ PPG PEC Test Data } \\
\hline $\begin{array}{c}\text { Test } \\
\#\end{array}$ & $\begin{array}{l}\text { Nominal Window Size } \\
\text { (in) }\end{array}$ & $\begin{array}{c}\text { Type of } \\
\text { Connections }\end{array}$ & $\begin{array}{c}\text { Day Light } \\
\text { Opening (in) }\end{array}$ & $\begin{array}{c}\text { Actual Glass } \\
\text { Thickness } \\
\text { (in) }\end{array}$ & $\begin{array}{c}\text { Actual } \\
\text { Polymer } \\
\text { Thickness (in) }\end{array}$ \\
\hline 1 & $24 \times 36 \times 1 / 4 \mathrm{AN}$ & Tape Only & $22.5^{\prime \prime} \times 33.75^{\prime \prime}$ & 0.225 & none \\
\hline 2 & $24 \times 36 \times 1 / 8 \mathrm{AN}$ & Tape Only & $22.5^{\prime \prime} \times 34.25 "$ & 0.115 & none \\
\hline 3 & $24 \times 36 \times 1 / 4 \mathrm{AN}$ & Tape Only & $22.5^{\prime \prime} \times 34.25 "$ & 0.225 & none \\
\hline 4 & $24 \times 36 \times 1 / 8 \mathrm{FT}$ & Tape Only & $22.1875^{\prime \prime}$ x $34^{\prime \prime}$ & 0.125 & none \\
\hline 5 & $24 \times 36 \times 1 / 8 \mathrm{FT}$ & Tape Only & $22.1875 "$ x 34" & 0.125 & none \\
\hline 6 & $24 \times 36 \times 1 / 8 \mathrm{AN}$ & Tape Only & $22.125 "$ x $34 "$ & 0.115 & none \\
\hline 7 & $24 \times 36 \times 1 / 8 \mathrm{AN}$ & Tape Only & $22.125 "$ x 34" & 0.115 & none \\
\hline 8 & $24 \times 36 \times 1 / 8 \mathrm{FT}$ & Tape Only & $22.1875 "$ x 33.875" & 0.125 & none \\
\hline 9 & $24 \times 36 \times 1 / 4$ AN 0.030 clear & Tape Only & $22.1875 "$ x 33.875" & 0.225 & 0.033 \\
\hline 10 & $24 \times 36 \times 1 / 8$ AN 0.030 clear & Tape Only & $22.125 "$ x $34 "$ & 0.115 & 0.032 \\
\hline 11 & $24 \times 36 \times 1 / 4$ AN 0.030 clear & Tape Only & $22.125^{\prime \prime}$ x 33.875" & 0.225 & 0.034 \\
\hline 12 & $24 \times 36 \times 1 / 8$ AN 0.030 clear & Tape Only & $22.125^{\prime \prime} \times 34^{\prime \prime}$ & 0.115 & 0.033 \\
\hline 13 & $24 \times 36 \times 1 / 4 \mathrm{AN}$ & Tape Only & $22.1875 "$ x 33.875" & 0.225 & none \\
\hline 14 & $24 \times 36 \times 1 / 8$ AN 0.030 clear & Spray 4 Sides & $22.5^{\prime \prime} \times 34.25^{\prime \prime}$ & 0.115 & 0.036 \\
\hline 15 & $24 \times 36 \times 1 / 8$ AN 0.015 clear & Spray 4 Sides & $22.5^{\prime \prime} \times 34.25 "$ & 0.115 & 0.0156 \\
\hline 16 & $48 \times 48 \times 1 / 4 \mathrm{AN}$ & Tape Only & $44.5^{\prime \prime} \times 46.5^{\prime \prime}$ & 0.219 & none \\
\hline 17 & $48 \times 48 \times 1 / 4$ AN 0.060 clear & Spray 4 Sides & $44.5^{\prime \prime} \times 46.1875 "$ & 0.221 & 0.062 \\
\hline 18 & $48 \times 48 \times 1 / 4$ AN 0.030 clear & Tape Only & $44.5^{\prime \prime}$ x 46.3125" & 0.221 & 0.037 \\
\hline 19 & $48 \times 48 \times 1 / 4$ AN 0.125 clear & Spray 4 Sides & $44.5 " \times 46.5 "$ & 0.224 & 0.119 \\
\hline 20 & $48 \times 48 \times 1 / 4$ AN 0.030 clear & Tape Only & $44.625 " \times 46.375^{\prime \prime}$ & 0.212 & 0.036 \\
\hline 21 & $48 \times 48 \times 1 / 4$ AN 0.030 clear & Tape Only & $44.25 " \times 46.5 "$ & 0.225 & none \\
\hline 22 & $48 \times 48 \times 1 / 4$ AN & Spray 4 Sides & $44.625^{\prime \prime} \times 46.375^{\prime \prime}$ & 0.221 & 0.0318 \\
\hline 23 & $48 \times 48 \times 1 / 4 \mathrm{AN}$ & Tape Only & $44.25 "$ x 46.5" & 0.230 & none \\
\hline
\end{tabular}

Two types of glazing materials (annealed and fully tempered) were coated with low modulus of elasticity (E), high adhesion clear polymer. Based on preliminary resistance functions and the test frame capacity, a range of glass and polymer thicknesses were specified to encompass a variety of window responses.

Each window was attached to a load controlled water pressure test tank with a steel mask corresponding to the nominal window size. The side of the window facing the inside of the test tank is denoted as the "blast" face and represents the exterior face of a window in a building. Therefore, the interior side of the window, with polymer coating, was visible. The test tank has a 4 -ft by 6 - $\mathrm{ft}$ opening and is 9-in deep. The mask was bolted to the test tank to decrease the opening to the nominal window size. The non-responding window frame, constructed out of two 4 -in by $1 / 4$-in aluminum plates that sandwich the glass lite, was bolted to the steel mask. A rubber gasket was placed between the tank/mask and mask/frame interfaces to create a watertight seal. After shimming the frame as required, the bolts were snugly tightened around the frame and tank perimeter. Instrumentation during each test included a combination of linear potentiometers, bi-axial strain gauges, and pressure gauges. The pressure gauge, 
mounted on the test tank sidewall, measured the tank water pressure, which was assumed equivalent to the applied pressure on the glass.

Comparisons between mode of failure, resistance function, and overall response for windows with and without clear polymer coating were made. Glass without clear polymer coating was tested first to serve as a baseline for comparison to coated glass and to determine the surface flaw parameters required in the glass failure prediction model (GFPM). As expected, the noncoated annealed glass fractured in large, jagged fragments, while the fullytempered glass fractured in small, smooth shards. Oval fracture patterns were also noted in the majority of tests, as seen in previous research and Figure 1. In most cases for polymer coated glass, the polymer failed by bridging over cracks locally near edges, as shown in Figure 2. Results from the quasi-static tests are summarized in Table 2. The polymer performed better when the glass broke into smaller, evenly distributed fragments because the polymer stress was less localized. PEC recommended a higher strength polymer with a higher modulus of elasticity to improve the polymer response at localized cracks. It was also suggested that, during a dynamic test, a polymer with less adhesion might help prevent tearing at localized cracks, which leads to polymer failure. Anecdotal evidence from Test 17 also supported the theory that less adhesion, through extensive cracking in this case, allowed the polymer to pull free from the glass earlier in time and absorb more energy through large displacements prior to polymer failure. After Test 17, it was possible to pull the polymer off the glass by hand, which was not possible during any other tests.

Table 2: Quasi-static test results.

\begin{tabular}{|c|c|c|c|c|c|c|c|c|c|c|}
\hline \multicolumn{3}{|c|}{ PPG PEC Test Data } & \multicolumn{5}{|c|}{ Glass Break } & \multicolumn{3}{|c|}{ Maximum Polymer failure } \\
\hline $\begin{array}{c}\text { Test } \\
\#\end{array}$ & $\begin{array}{l}\text { Nominal Window Size } \\
\text { (in) }\end{array}$ & $\begin{array}{c}\text { Type of } \\
\text { Connections }\end{array}$ & $\begin{array}{l}\text { Pressure } \\
\text { (psi) }\end{array}$ & $\begin{array}{l}\text { midpoint } \\
\text { deflection } \\
\text { (in) }\end{array}$ & $\begin{array}{l}1 / 4 \text { point } \\
\text { deflection } \\
\text { (in) }\end{array}$ & $\begin{array}{l}\text { Strain } 1 \\
\text { (ustrain) }\end{array}$ & $\begin{array}{c}\text { Strain } 3 \\
(\mu \text { strain })\end{array}$ & $\begin{array}{l}\text { Pressure } \\
\text { (psi) }\end{array}$ & $\begin{array}{l}\text { midpoint } \\
\text { deflection } \\
\text { (in) }\end{array}$ & $\begin{array}{l}\text { 1/4 point } \\
\text { deflection } \\
\text { (in) }\end{array}$ \\
\hline 1 & $24 \times 36 \times 1 / 4 \mathrm{AN}$ & Tape Only & 2.84 & 0.487 & 0.334 & & & & & \\
\hline 2 & $24 \times 36 \times 1 / 8 \mathrm{AN}^{*}$ & Tape Only & 1.78 & 0.657 & 0.437 & & & & & \\
\hline 3 & $24 \times 36 \times 1 / 4 \mathrm{AN}^{*}$ & Tape Only & 2.33 & 0.360 & 0.228 & & & & & \\
\hline 4 & $24 \times 36 \times 1 / 8$ FT & Tape Only & 8.21 & 1.370 & 1.069 & & & & & \\
\hline 5 & $24 \times 36 \times 1 / 8 \mathrm{FT}$ & Tape Only & 8.01 & 1.362 & 1.058 & & & & & \\
\hline 6 & $24 \times 36 \times 1 / 8 \mathrm{AN}$ & Tape Only & 1.59 & 0.486 & did not use & & & & & \\
\hline 7 & $24 \times 36 \times 1 / 8 \mathrm{AN}$ & Tape Only & 1.15 & 0.487 & did not use & 501 & 330 & & & \\
\hline 8 & $24 \times 36 \times 1 / 8 \mathrm{FT}$ & Tape Only & 7.40 & 1.300 & 1.029 & 833 & 1202 & & & \\
\hline 9 & $24 \times 36 \times 1 / 4$ AN 0.030 clear & Tape Only & 0.592 & 0.10 & 0.06 & \multicolumn{2}{|c|}{ Glass pre-cracked } & 1.195 & 0.50 & 0.39 \\
\hline 10 & $24 \times 36 \times 1 / 8$ AN 0.030 clear & Tape Only & 1.927 & 0.58 & 0.38 & & & 0.362 & 2.72 & 1.91 \\
\hline 11 & $24 \times 36 \times 1 / 4$ AN 0.030 clear & Tape Only & 5.066 & 0.71 & 0.50 & 1051 & 653 & 0.734 & 4.28 & 2.61 \\
\hline 12 & $24 \times 36 \times 1 / 8$ AN 0.030 clear & Tape Only & 0.822 & 0.35 & 0.20 & 466 & 234 & 0.187 & 0.90 & 0.62 \\
\hline 13 & $24 \times 36 \times 1 / 4$ AN & Tape Only & 2.71 & 0.418 & 0.283 & 658 & 294 & & & \\
\hline 14 & $24 \times 36 \times 1 / 8$ AN 0.030 clear & Spray 4 sides & \multicolumn{8}{|c|}{ Glass Pre-Cracked } \\
\hline 15 & $24 \times 36 \times 1 / 8$ AN 0.015 clear & Spray 4 sides & 1.179 & 0.45 & 0.29 & & & & & \\
\hline 16 & $48 \times 48 \times 1 / 4 \mathrm{AN}$ & Tape Only & 1.794 & 0.79 & 0.55 & & & & & \\
\hline 17 & $48 \times 48 \times 1 / 4$ AN 0.060 clear & Spray 4 sides & 1.284 & 0.75 & 0.52 & & & 0.234 & 3.35 & 2.46 \\
\hline $18+$ & $48 \times 48 \times 1 / 4$ AN 0.030 clear & Tape Only & 0.634 & 0.43 & 0.28 & 219 & 247 & 0.183 & 1.81 & 0.70 \\
\hline 19 & $48 \times 48 \times 1 / 4$ AN 0.125 clear & Spray 4 sides & 1.715 & 0.78 & 0.56 & & & 0.210 & 2.26 & 1.24 \\
\hline 20 & $48 \times 48 \times 1 / 4$ AN 0.030 clear & Tape Only & 1.223 & 0.72 & 0.50 & & & 0.236 & 2.78 & 1.49 \\
\hline 21 & $48 \times 48 \times 1 / 4$ AN 0.030 clear & Spray 4 sides & 0.778 & 0.47 & 0.32 & \multicolumn{2}{|c|}{ Glass Pre-Cracked } & 0.228 & 2.12 & 0.92 \\
\hline 22 & $48 \times 48 \times 1 / 4$ AN & Tape Only & 1.047 & 0.54 & 0.35 & & & & & \\
\hline 23 & $48 \times 48 \times 1 / 4 \mathrm{AN}$ & Tape Only & 1.184 & 0.59 & 0.39 & 317 & 287 & & & \\
\hline
\end{tabular}




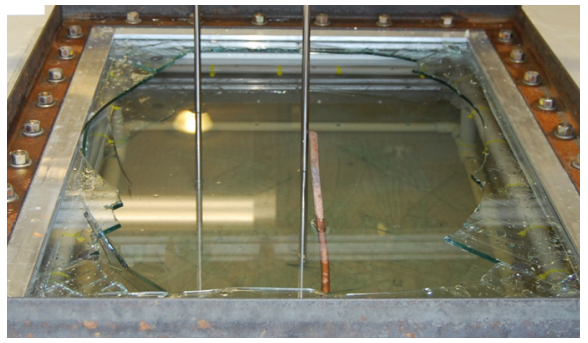

Figure 1: Oval fracture pattern (no poly).

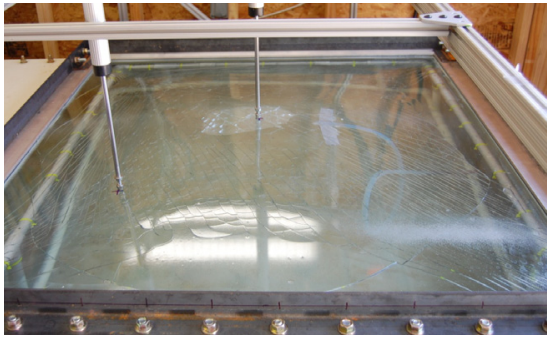

Figure 2: Polymer test with bridging.

\section{Analysis and resistance function development}

The pressure and displacement histories from each test were used to determine a static resistance function for each window assembly. The measured tank pressure was equivalent to the resistance of the window assembly in this analysis. Figure 3 illustrates the static resistance functions for tests 16-23. The first slope represents the glass resistance up to fracture (AN - annealed). The second positive slope represents the polymer resistance after glass fracture. PEC evaluated the polymer contribution in two regimes: small displacement glasspolymer response and large displacement polymer response only. Comparisons of tests with and without polymer coating show no stiffness enhancement prior to glass fracture for clear polymer coated glass, as shown in Figure 4 (again for tests 16-23). In addition, different polymer connections (tape only vs. spray all sides) performed similarly during static tests. The shim thickness was noted to have a small effect on the stiffness prior to glass failure because the thickness difference changed the amount of fixity at the support. Therefore, the main variables that affected glass break were window size, type of glass, and glass thickness.

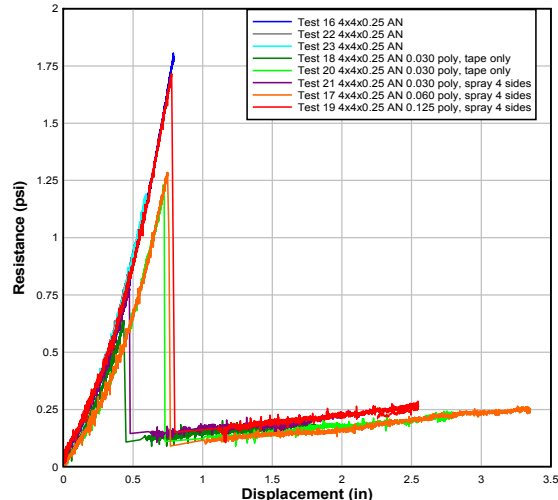

Figure 3: Glass/poly resistance (16-23).

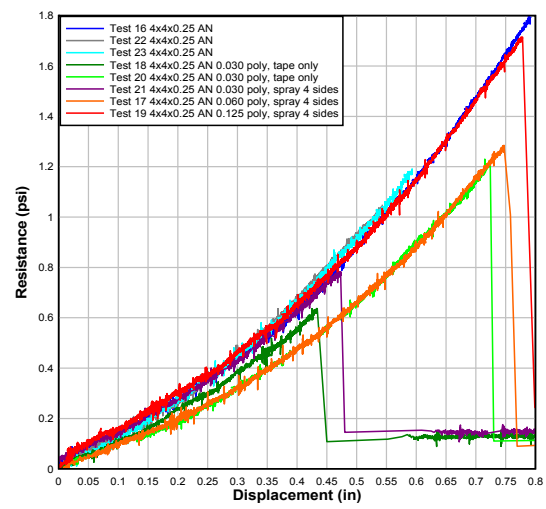

Figure 4: Glass resistance (1623). 
The polymer response after glass fracture thus only varies with the polymer type and polymer thickness. Based on the static test results, a polymer thickness range of 0.030 -in to 0.060 -in was determined to be most effective. For example, Test 15 had a 0.015 -in thick polymer coating and experienced polymer failure concurrent with glass failure; therefore, statically the 0.015 -in thickness does not enhance the capacity of the system. Test 19 evaluated a window with 0.125 -in thick polymer coating, which performed similar to 0.060 -in polymer coated windows at best, illustrating the lack of benefit above a thickness of 0.060-in. The maximum polymer displacement of 4.3-in occurred during Test 11 for a $2 \times 3$ AN window with 0.030 -in clear polymer. For a $4 \times 4$ AN window, a maximum displacement of 3.4-in occurred during Test 17 using 0.060-in thick polymer coating. Overall, the polymer membrane response, while adding significant ductility to the glazing system, was lower than expected based on preliminary dynamic predictions. Therefore, polymer rate effects to be determined through dynamic (blast) testing were deemed essential.

\section{Dynamic (explosive) tests}

To evaluate the performance of the polymer coated windows under dynamic loads (strain rate effects and failure mechanisms), five full-scale explosive tests were completed at a Southwest Research Institute test site near Yancey, Texas. Each blast test investigated two windows mounted in a single steel reaction structure. The reaction structure was placed at standoffs between $120-\mathrm{ft}$ to $265-\mathrm{ft}$ for charges ranging from 200 to $1200 \mathrm{lbs}$ of ANFO (Ammonium Nitrate and Fuel Oil). The test matrix included eight test specimens and accounted for three test variables: size of window, polymer thickness, and polymer modulus of elasticity. Several parameters were held constant during the dynamic testing including glass thickness, glass type, polymer adhesion, and connection type. PPG performed the clear polymer application at PPG Industries and then shipped the coated glass to PEC for framing similar to that used in the quasi-static tests.

Two nominal window sizes were tested; 2 -ft $\times 3$-ft and 4 -ft $\times 4$ - $\mathrm{ft}$ (width $\times$ height). The only connection between the aluminum window frame and clear polymer coated glazing was a 1.25-in, 3M VHB Structural Glazing (grey) Tape G23F applied to both sides (tape only). Essentially, the glazing was confined within the aluminum frame for ease of construction and shipment. All frame pieces were 6061-T6 aluminum. In all tests, 1/4-in annealed glass was coated with low adhesion clear polymer. An assumed actual thickness of 0.225 -in was used in the calculations. Based on preliminary resistance functions and the test frame capacity, a range of polymer thicknesses and modulus of elasticity (E) types were specified to encompass a variety of window lay-ups.

PEC designed a steel reaction structure with two 46-in square openings to accommodate two windows per test, as shown in Figures 5 and 6 . The closed box design prevented pressure from wrapping around to the back face of the windows. To decrease the window opening for the $2-\mathrm{ft}$ by $3-\mathrm{ft}$ windows, two steel masks with 22.75 -in by 34.5 -in openings were bolted to the reaction structure when needed. The test specimens were designed to bolt directly to the 


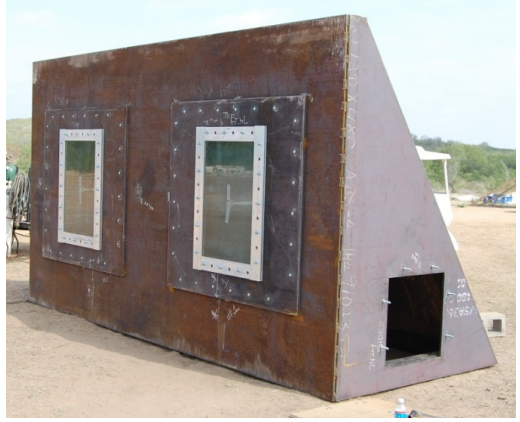

Figure 5: Steel reaction "box".

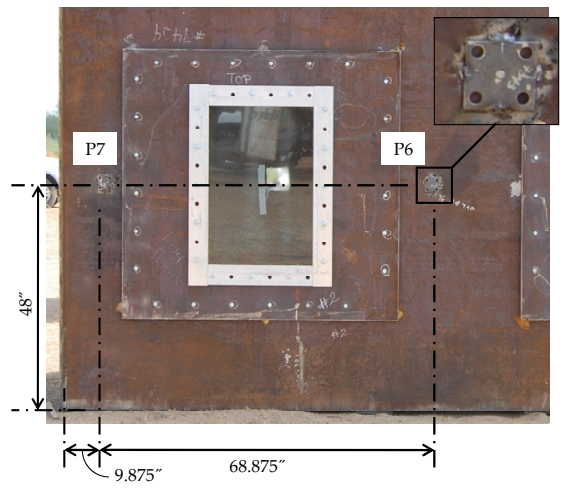

Figure 6: Pressure gage locations.

reaction structure. Openings for instrumentation were also provided on the front and back face for the pressure and scratch gauges, respectively.

The goal of the dynamic clear polymer tests was to evaluate the rate sensitivity and dynamic failure mechanism of clear polymer coated glass. Therefore, charge weights and standoffs were selected to cause membrane response at large post-glass fracture deformations. Six of the eight window specimens (two windows were retested) experienced membrane response. The results from each dynamic test are summarized in Table 3. The displacement was used in combination with the pressure histories and high-speed video

Table 3: $\quad$ Dynamic (explosive) test matrix and results.

\begin{tabular}{|c|c|c|c|c|c|c|c|c|c|}
\hline \multirow[b]{2}{*}{$\begin{array}{c}\text { Test } \\
\#\end{array}$} & \multirow[b]{2}{*}{$\begin{array}{l}\text { Window } \\
\text { Type }\end{array}$} & \multirow[b]{2}{*}{\begin{tabular}{|} 
Scratch \\
Deflection \\
(in)
\end{tabular}} & \multicolumn{2}{|c|}{ Center Gauge (P6) } & \multicolumn{2}{|c|}{ Side Gauge (P7) } & \multicolumn{2}{|c|}{ TNT Equivalency } & \multirow[b]{2}{*}{ Test Notes } \\
\hline & & & $\begin{array}{c}\text { Peak } \\
\text { Pressure } \\
\text { (psi) }\end{array}$ & $\begin{array}{c}\text { Max } \\
\text { Impulse } \\
\text { (psi-msec) }\end{array}$ & $\begin{array}{c}\text { Peak } \\
\text { Pressure } \\
\text { (psi) }\end{array}$ & $\begin{array}{c}\text { Max } \\
\text { Impulse } \\
\text { (psi-msec) }\end{array}$ & $\begin{array}{l}\text { Average } \\
\text { for } \\
\text { Pressure }\end{array}$ & $\begin{array}{l}\text { Average } \\
\text { for } \\
\text { Impulse }\end{array}$ & \\
\hline $1 \mathrm{~A}$ & $\begin{array}{l}2 \times 3 \times 1 / 4 \mathrm{AN} \\
0.030 \text { Low } \mathrm{E}\end{array}$ & 0.50 & 6.10 & 19.3 & 5.70 & 14.9 & 1.50 & 0.40 & no break \\
\hline $1 \mathrm{~B}$ & $\begin{array}{l}2 \times 3 \times 1 / 4 \text { AN } \\
0.030 \text { High E }\end{array}$ & 0.50 & 6.10 & 19.3 & 5.70 & 14.9 & 1.50 & 0.40 & no break \\
\hline $2 \mathrm{~A}$ & $\begin{array}{l}2 \times 3 \times 1 / 4 \mathrm{AN} \\
0.030 \text { Low } \mathrm{E}\end{array}$ & N/A & 8.80 & 27.5 & 8.30 & 20.5 & 1.43 & 0.36 & $\begin{array}{c}\text { membrane } \\
\text { response }\end{array}$ \\
\hline $2 \mathrm{~B}$ & $\begin{array}{l}2 \times 3 \times 1 / 4 \text { AN } \\
0.030 \text { High E }\end{array}$ & 6.19 & 8.80 & 27.5 & 8.30 & 20.5 & 1.43 & 0.36 & $\begin{array}{l}\text { membrane } \\
\text { response }\end{array}$ \\
\hline $3 \mathrm{~A}$ & $\begin{array}{l}2 \times 3 \times 1 / 4 \mathrm{AN} \\
0.030 \text { Low } \mathrm{E}\end{array}$ & 6.13 & 7.59 & 27.0 & 7.39 & 25.1 & 1.39 & 0.40 & $\begin{array}{c}\text { membrane } \\
\text { response }\end{array}$ \\
\hline 3B & $\begin{array}{l}4 \times 4 \times 1 / 4 \text { AN } \\
0.060 \text { High E } \\
\end{array}$ & 12.38 & 7.59 & 27.0 & 7.39 & 25.1 & 1.39 & 0.40 & $\begin{array}{c}\text { membrane } \\
\text { response }\end{array}$ \\
\hline $4 \mathrm{~A}$ & $\begin{array}{l}4 \times 4 \times 1 / 4 \mathrm{AN} \\
0.030 \text { Low } \mathrm{E}\end{array}$ & 9.50 & 5.25 & 18.49 & 5.08 & 27.13 & 1.26 & 0.35 & $\begin{array}{c}\text { membrane } \\
\text { response }\end{array}$ \\
\hline $4 \mathrm{~B}$ & $\begin{array}{l}4 \times 4 \times 1 / 4 \text { AN } \\
0.030 \text { High E }\end{array}$ & 10.00 & 5.25 & 18.49 & 5.08 & 27.13 & 1.26 & 0.35 & $\begin{array}{c}\text { membrane } \\
\text { response }\end{array}$ \\
\hline $5 \mathrm{~A}$ & $\begin{array}{l}2 \times 3 \times 1 / 4 \mathrm{AN} \\
0.015 \text { High E }\end{array}$ & 3.00 & 8.02 & 22.91 & 7.59 & 30.13 & 1.52 & 0.31 & $\begin{array}{l}\text { tear prior to } \\
\text { membrane }\end{array}$ \\
\hline $5 \mathrm{~B}$ & $\begin{array}{l}2 \times 3 \times 1 / 4 \text { AN } \\
0.030 \text { High E }\end{array}$ & 1.13 & 8.02 & 22.91 & 7.59 & 30.13 & 1.52 & 0.31 & no break \\
\hline
\end{tabular}


collected. The high-speed video yielded a clear picture of the window response and failure mechanism. In general, the high-speed video shows the significant deformation of glazing specimens during inbound and rebound response.

In general, the clear polymer coated windows performed as predicted by elongating and bridging over cracks after glass failure in the oval yield line pattern noted in the static tests. Tested windows from Test 2 are shown in Figure 7. The membrane is shown to be intact for both configurations, although more glass was lost off of the membrane during rebound in the High E test (b).

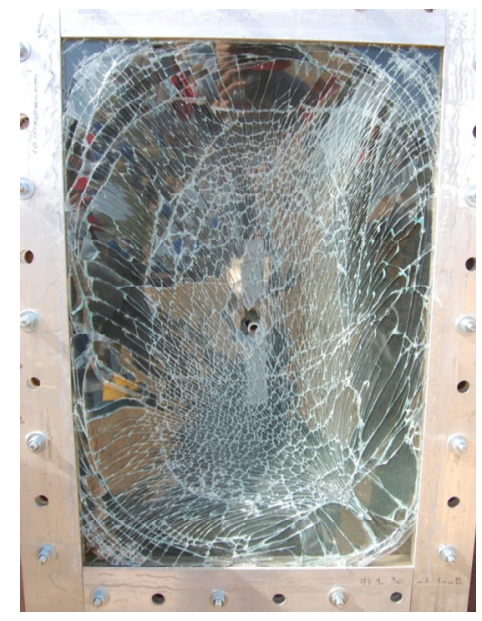

a) Test $2 \mathrm{~A}-2 \times 3 \times 1 / 4$ AN 030 Low E

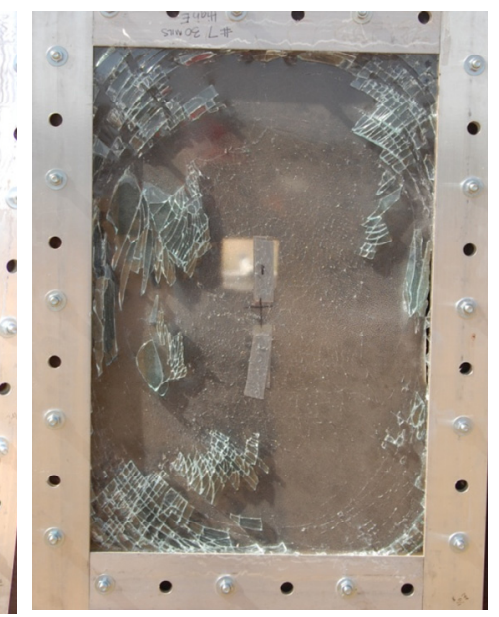

b) Test $2 \mathrm{~B}-2 \times 3 \times 1 / 4$ AN 0.030 High $\mathrm{E}$

Figure 7: Failure mechanism test 2.

The energy absorption through large tensile membrane response indicates that clear polymer is extremely load rate sensitive material. Small tears in the clear polymer were noted in several tests; however, this did not constitute failure and the majority of the glass fragments remained on the outside of the reaction structure. Glass is also a rate sensitive material and produced smaller shards during the dynamic testing. Smaller glass shards combined with less adhesion between the polymer and glass allowed the polymer to release from the glass and distribute the load more uniformly; which provided more places for the polymer to bridge minimizing tears. This results in much larger maximum displacements before failure than observed in the static tests.

A dynamic resistance function for a clear polymer coated window was determined in two parts using the Glass Failure Prediction Model (GFPM) developed by Beason et al. [1] for glass response up to fracture and WinGard [2] equations originally developed by Timoshenko/Urgural for polymer membrane response. The GFPM relates the probability of failure of glass, surface flaw characteristics ( $\mathrm{m}$ and $\mathrm{k}$ ), and induced stresses by combining a statistical failure theory for brittle materials (Weibull distribution) with results of geometrically non-linear plate analysis. The surface flaw parameter, $\mathrm{m}$, of 6.79 was determined 
from the static test results. Measured loads from the blast tests (averages of gages 6 and 7 on the test fixture) were used in the analysis.

Figure 8 illustrates the dynamic resistance function developed for each clear polymer coated window.

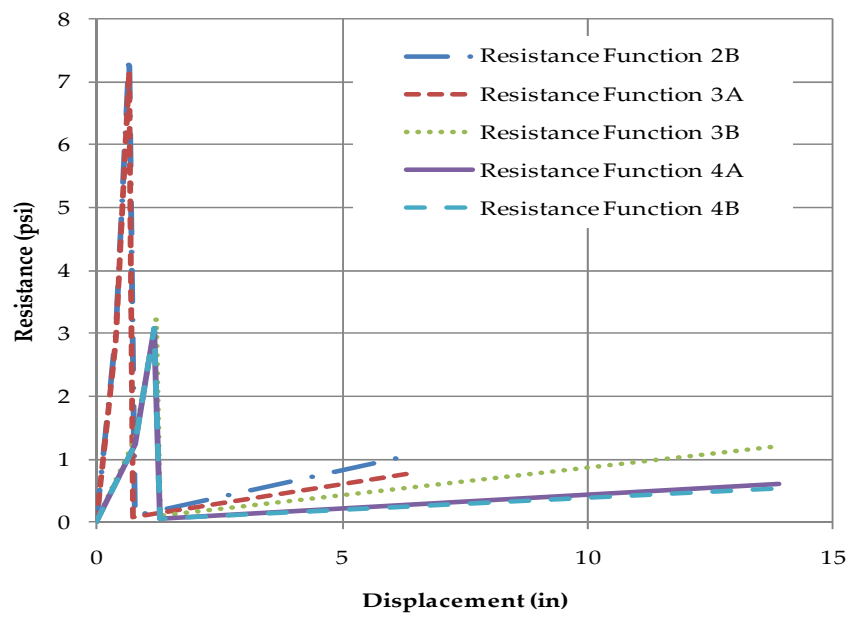

Figure 8: Resistance functions developed from tests and analysis.

The theoretical membrane equations were applied to clear polymer by changing two material properties: Poisson's ratio and modulus of elasticity. A Poisson's ratio of 0.5 was assumed for the clear polymer resistance calculations. An equation for modulus of elasticity in terms of strain across the short span was determined by back calculating a modulus at several deflections for each static clear polymer coated window test. A dynamic failure deflection criterion of $30 \%$ of the short span was selected, based on the observed deflection to short span ratio for dynamic tests that experienced significant membrane response. Using the dynamic resistance function and pressure-time history in the SBEDS [3] general SDOF template, the DIF was iterated until the predicted deflection matched the measured deflection. The clear polymer was assumed to have a linear dynamic resistance function defined by the peak dynamic resistance (maximum clear polymer resistance scaled by the DIF) and assumed failure deflection.

\section{Conclusions}

The blast tests have determined that a minimum thickness of clear polymer of 0.030 -in is required to prevent tearing and premature failure of the polymer. Similarly, based on static test results, it is doubtful that a thickness in excess of 0.060 -in would be of additional benefit. The low adhesion specimen (glass that is not prepped and primed) seemed to perform well during blast tests, while the modulus of elasticity (high-E vs. low-E) had a very small change in polymer 
performance. Both the tape only and spray over all sides connections seem to work adequately.

Comparisons with other "blast resistant" window configurations (security film and laminated glass), as made using range-to-effect (RTE) calculations, show that clear polymer coated glass in the 0.030 -in to 0.060 -in thickness range perform similarly and in some cases better than 7-mil polyester film and laminated glass (0.030 interlayer).

\section{Acknowledgements}

The authors would like to thank Truman Wilt, Mike Mulligan, Howard Senkfor, and Dan Bratys for their support of the development of this technology.

\section{References}

[1] Beason, W. Lynn and Morgan, James R., "Glass Failure Prediction Model," ASCE Journal of Structural Engineer, Vol 110, No.2, February 1984.

[2] "Window Glazing Analysis Response and Design, WinGARD," US General services Administration, Public Buildings Service, prepared by Applied Research Associates, August 2005.

[3] "Users Guide for the Single-Degree-of-Freedom Blast Effects Design Spreadsheets (SBEDS)," US Army Corps of Engineers, Omaha District Protective Design Center (PDC), prepared by Protection Engineering Consultants, September 2006. 